\title{
TEMPERATURE CORRECTION OF DEFLECTIONS AND BACKCALCULATED ELASTICITY MODULI DETERMINED FROM FALLING WEIGHT DEFLECTOMETER MEASUREMENTS ON ASPHALT PAVEMENTS
}

\author{
Ilja Březina*, Ondřej Machel, Tomáš Zav̌̌el \\ Transport Research Centre (CDV), Brno, Czech Republic \\ *E-mail of corresponding author: ilja.brezina@cdv.cz
}

\section{Resume}

The evaluation of the bearing capacity of asphalt pavements is usually performed by analysing the deflections measured by a Falling Weight Deflectometer (FWD). The deflection changes with the pavement temperature. In evaluation is necessary to consider the thermal gradient of pavement and perform the temperature correction. The article contains an analysis of effects of the pavement temperature on FWD results on the long-term monitored sections. The temperature correction was performed on measured deflections or back-calculated elasticity moduli. The moduli recalculated to the temperature of $20^{\circ} \mathrm{C}$ according to both procedures were similar. Comparison of moduli determined by recalculation to moduli backcalculated from the deflection bowls measured at the temperature of $20^{\circ} \mathrm{C}$, has proven smaller differences for the moduli determined from the deflection bowl corrected to the temperature of $20^{\circ} \mathrm{C}$.

Available online: https://doi.org/10.26552/com.C.2022.1.D1-D8

\section{Article info}

Received 3 March 2021

Accepted 13 May 2021

Online 18 October 2021

\section{Keywords:}

asphalt pavement, elasticity modulus, deflection, deflectometer (FWD), temperature correction

\section{Introduction}

Asphalt layers of flexible pavements contain a bituminous binder that is sensitive to temperature changes occurring in a pavement due to air temperature changes. In [1] it is stated that the temperature of asphalt layers not only changes within the year, but within a single day, as well, when changes of temperature gradients occur in asphalt layers. A change in the stiffness of a bituminous binder used in asphalt mixtures causes a change in their stiffness. Therefore, a deflection measured in one place in a different time will have different values. This has to be considered in diagnostics and evaluation of asphalt pavement bearing capacity. The necessity of temperature correction has already been clearly proven in numerous scientific publications, e. g. [2-11].

Due to the fact that the temperature gradient in a pavement can be high (particularly during the sunny summer days), some requirements, limiting measurements in relation to pavement temperature, can be found. According to [12], the temperature of pavement during the measurement has to be in the range of 0 $30{ }^{\circ} \mathrm{C}$. The temperature of pavement is characterized by the average temperature of asphalt layers, which is considered as the temperature in a certain depth under the pavement surface, e. g. $40 \mathrm{~mm}$ [1-12] or $50 \mathrm{~mm}$ [10].
As the average temperature of asphalt layers should be determined at every diagnostic point, a non-destructive method, based on the surface temperature of pavement and temperature gradients during the day, is optimum for its determination. According to [13], the average temperature of asphalt layers can be determined from the surface temperature of asphalt pavement and the temperature difference between the surface temperature and the average temperature of asphalt layers. Other ways of predicting temperature in asphalt pavement, based on the pavement surface temperature, can be found e. g. in [14] or [15].

Two approaches of temperature correction can be used in the evaluation process of data from an FWD device. The first is the temperature corrections of deflections, which are subsequently used for backcalculation of elasticity moduli. Possible approaches, used for the temperature correction of deflections, are presented e. g. in [6, 10]. An important finding, regarding the temperature correction of deflections, is that the effect of temperature decreases with growing distance from the load axis and can be neglected at a certain distance. According to [10], the effect of temperature on deflections can be neglected at a distance longer than $600 \mathrm{~mm}$ from the load axis d. Different impact of temperature on deflections at various distances from the load axis was also proven in [6]. 
Table 1 Composition of tested pavements

\begin{tabular}{ccccc}
\hline \multirow{2}{*}{ Section } & \multicolumn{2}{c}{ Thickness of layer $(\mathrm{mm})$} \\
& Asphalt & Base & Subbase & Total \\
\hline 1 & 190 & 200 & 200 & 590 \\
2 & 100 & 400 & 0 & 500 \\
3 & 110 & 200 & 200 & 510 \\
4 & 350 & 450 & 0 & 800 \\
5 & 70 & 450 & 0 & 520 \\
6 & 180 & 400 & 0 & 580 \\
7 & 250 & 200 & 400 & 850 \\
9 & 140 & 400 & 0 & 540 \\
10 & 120 & 300 & 0 & 420 \\
\hline
\end{tabular}

The other option is the back-calculation of elasticity moduli for a specific temperature occurring during the measurement and temperature correction of the backcalculated moduli. Various reference temperatures are used worldwide depending on the next use (calculation of residual life, design of overlay thickness, etc.) and relates to used method. The value of $20{ }^{\circ} \mathrm{C}$ [4], or potentially $25{ }^{\circ} \mathrm{C}$ [5], is frequently used as a reference temperature. Equation published in [6] allows to select own reference temperature (e. g. $20{ }^{\circ} \mathrm{C}, 25{ }^{\circ} \mathrm{C}$ ). The method of the elasticity moduli temperature correction is described in numerous publications, e. g. [4, 7-8, 11]. An extensive overview of models for the temperature correction of the asphalt layers elasticity moduli by different authors is shown in [2].

As the two mentioned approaches can lead to different outputs, the aim of the presented study was to investigate differences in the back-calculated moduli recalculated to the reference temperature of $20^{\circ} \mathrm{C}$ using both approaches.

\section{Experimental sections and methodology}

The effect of temperature on measured deflections and back-calculated elasticity moduli was investigated on 10 testing sections with different composition of asphalt pavement structures (Table 1). Three points with the interval of $1 \mathrm{~m}$ were selected for repeated testing in each section.

Deflections were generated and registered by the deflectometer FWD RODOS. Twenty cycles were performed at each testing point. Each cycle was executed at different temperature and consisted of three drops with the load force of $50 \mathrm{kN}$.

Temperature of air and pavement on surface, in the depth of $30-40 \mathrm{~mm}$ and $70-90 \mathrm{~mm}$ was registered during the measurements in the vicinity of the tested point. The total temperature range was $1-35^{\circ} \mathrm{C}$.

The modulus of elasticity of individual pavement layers was determined by back-calculation using the computer program PADAL.

\section{Temperature correction of backcalculated elasticity moduli}

This approach uses the elasticity moduli calculated for a specific temperature occurring during the measurements. These are corrected (recalculated) to a "reference" temperature.

The plot of temperature against elasticity moduli back-calculated directly from a measured deflection bowl and determination of the regression curve was the first step in determination of the temperature effect on asphalt layers elasticity moduli. The example in Figure 1 shows the back-calculated elasticity moduli derived from all the repeated measurements at three points of the section 5 that were performed at different times and temperatures. The coefficient of determination is high and the temperature effect on back-calculated modulus is evident.

The temperature correction coefficients of each section, intended for the recalculation of the backcalculated elasticity moduli to the reference temperature of $20{ }^{\circ} \mathrm{C}$, were derived from the regression curve using the formula:

$c_{E}=E_{20} / E_{T}$,

where:

$c_{E}=$ temperature correction coefficient for modulus of elasticity [-],

$E_{20}=$ elasticity modulus of asphalt layers at the temperature of $20^{\circ} \mathrm{C}$ calculated from the regression curve [MPa],

$E_{T}=$ elasticity modulus of asphalt layers at the temperature $T$ calculated from the regression curve [MPa].

The set of curves, representing the calculated temperature correction coefficients (Figure 2) was used for determination of a general formula:

$c_{E}=e^{-0,0387 \cdot(20-T)}$.

Using this, the recalculation of elasticity modulus to the reference temperature of $20^{\circ} \mathrm{C}$ was determined in the form: 


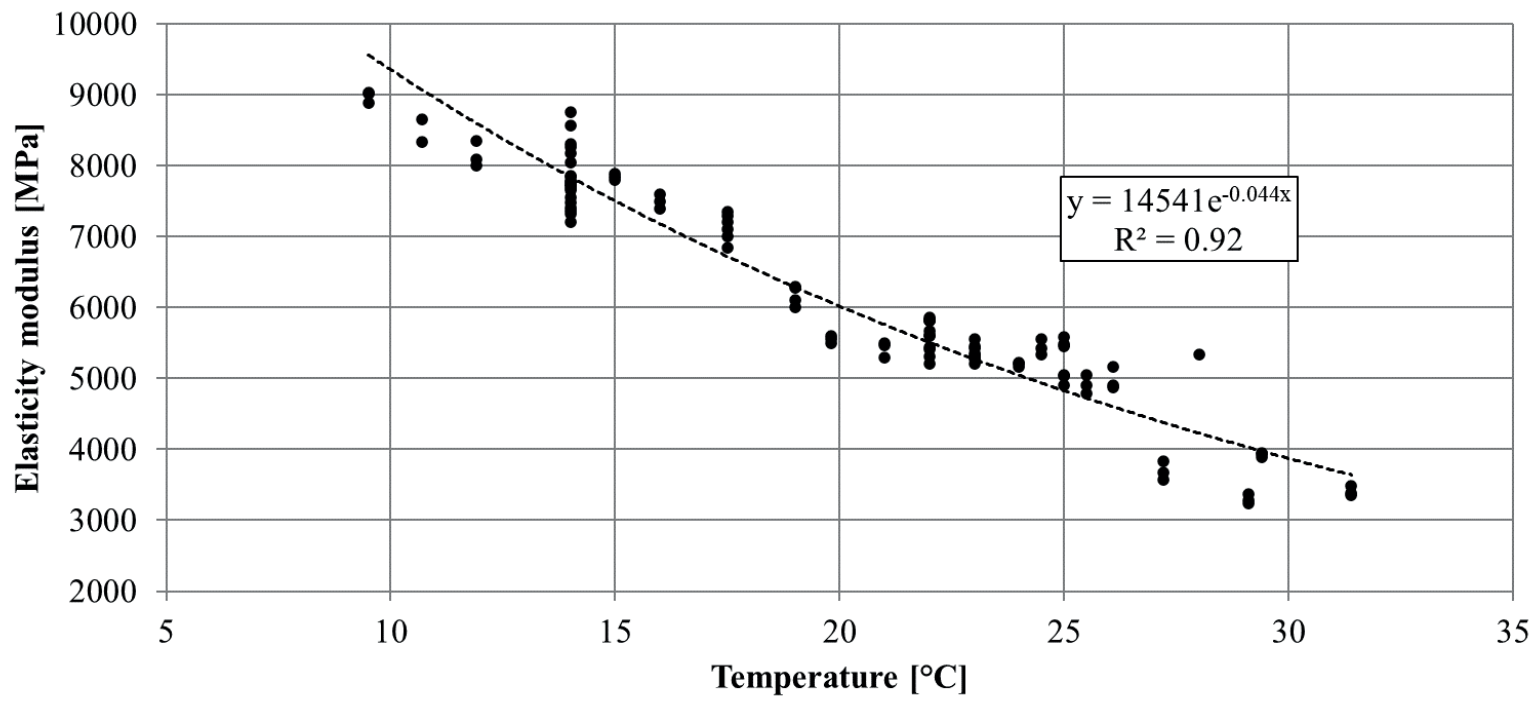

Figure 1 Variation of the asphalt layers elasticity moduli with temperature (section 5)

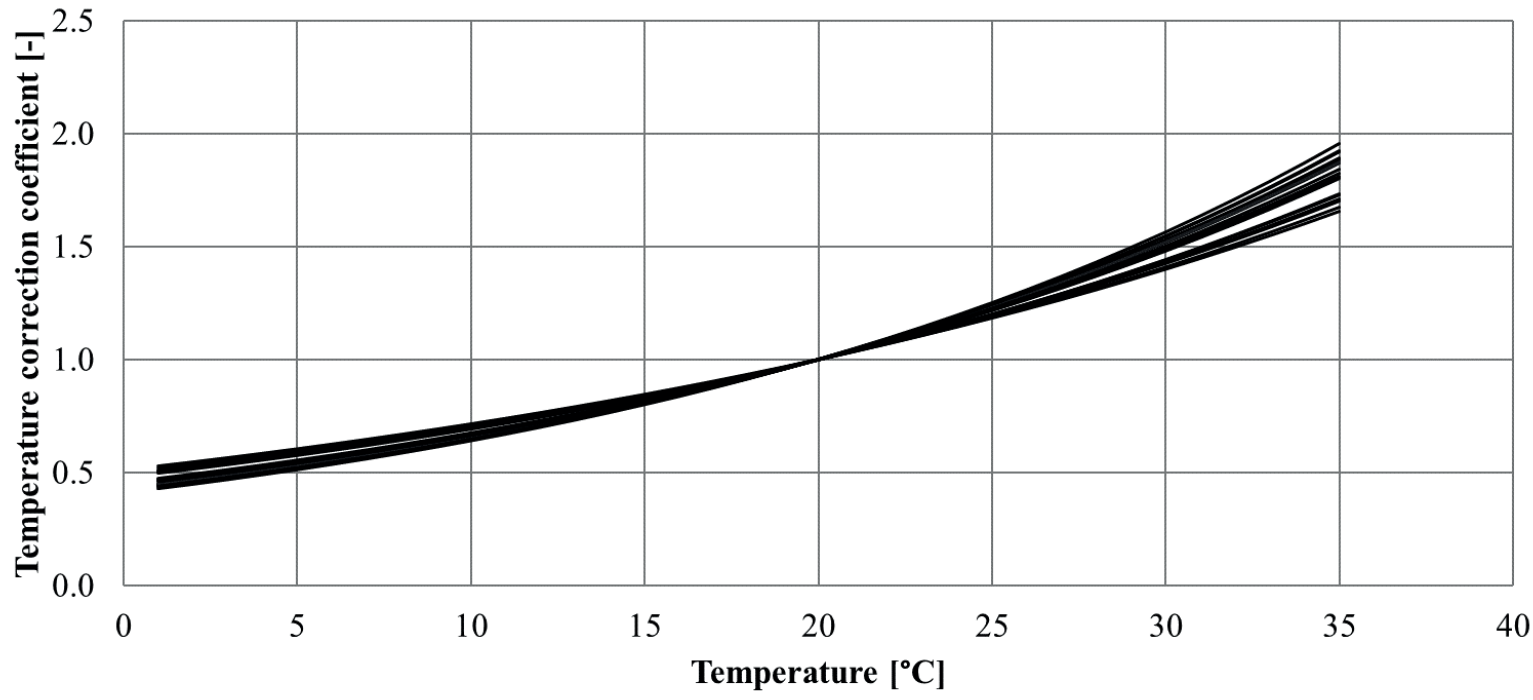

Figure 2 Calculated temperature correction coefficients

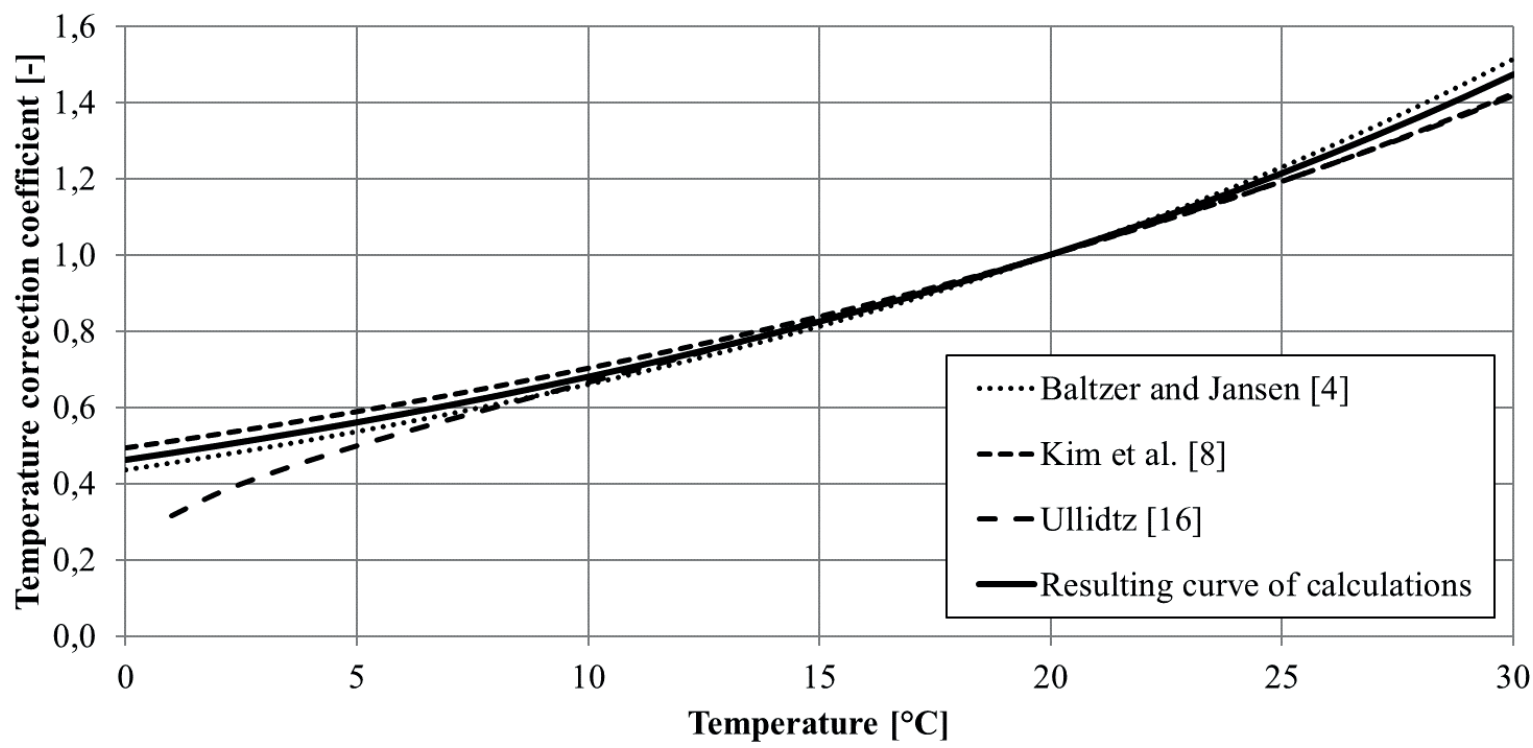

Figure 3 Comparison of determined correction to results of other authors 


$$
E_{20, \text { cor }}=E_{T} \cdot e^{-0.0387 \cdot(20-T)},
$$

where:

$E_{20, \text { cor }}=$ elasticity modulus of asphalt layers corrected to the reference temperature of $20^{\circ} \mathrm{C}$ [MPa],

$E_{T}=$ back-calculated elasticity modulus of asphalt layers for the test temperature $T[\mathrm{MPa}]$,

$T=$ test temperature of asphalt layers in the depth of $40 \mathrm{~mm}\left[{ }^{\circ} \mathrm{C}\right]$.

The determined temperature correction coefficients of elasticity modulus of asphalt layers are similar to previously published results [4, 8, 16] (see Figure 3).

\section{Temperature correction of measured deflections}

The direct correction of deflections is another option how to consider the effect of temperature. To do this, correction coefficients must be known. Therefore, the deflections measured at the position of sensors were plotted against the test temperature and a regression curve was derived (Figure 4). The example in Figure 4 that shows deflections from repeated measurements at the same point(s) at different times and temperature conditions, confirms the linear dependency for all the distances of sensors and variability of the temperature effect. The change in deflection due to the temperature variation is the most significant in the case of the central deflection (the distance of $0 \mathrm{~mm}$ from the load axis) and gradually decrease for the more distant sensors.

The temperature correction coefficients for each sensor to the reference temperature of $20{ }^{\circ} \mathrm{C}$ were derived from the regression curve using the formula:

$c_{d}=d_{20} / d_{T}$,

where:

$c_{d}=$ temperature correction coefficient for deflections [-],

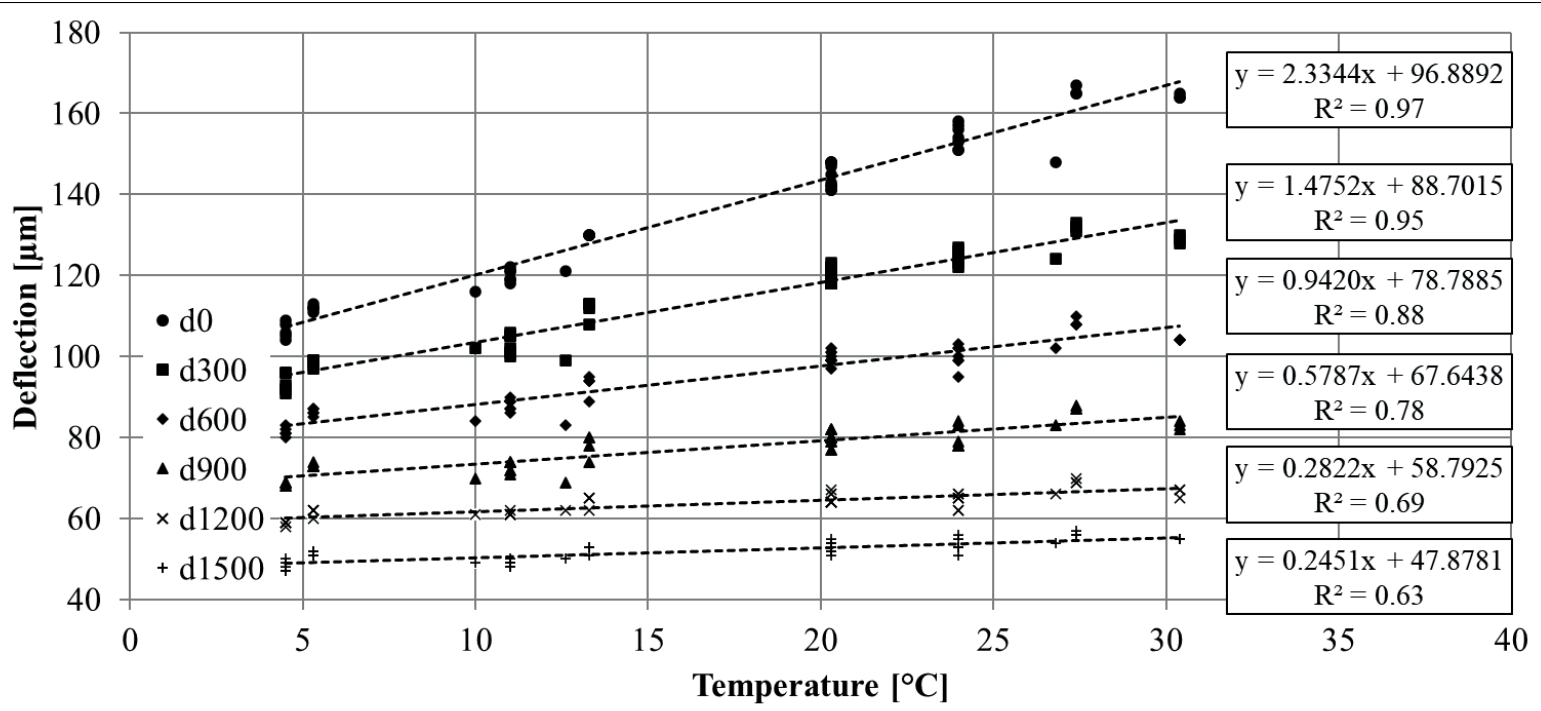

Figure 4 Change of deflections with temperature (section 5)

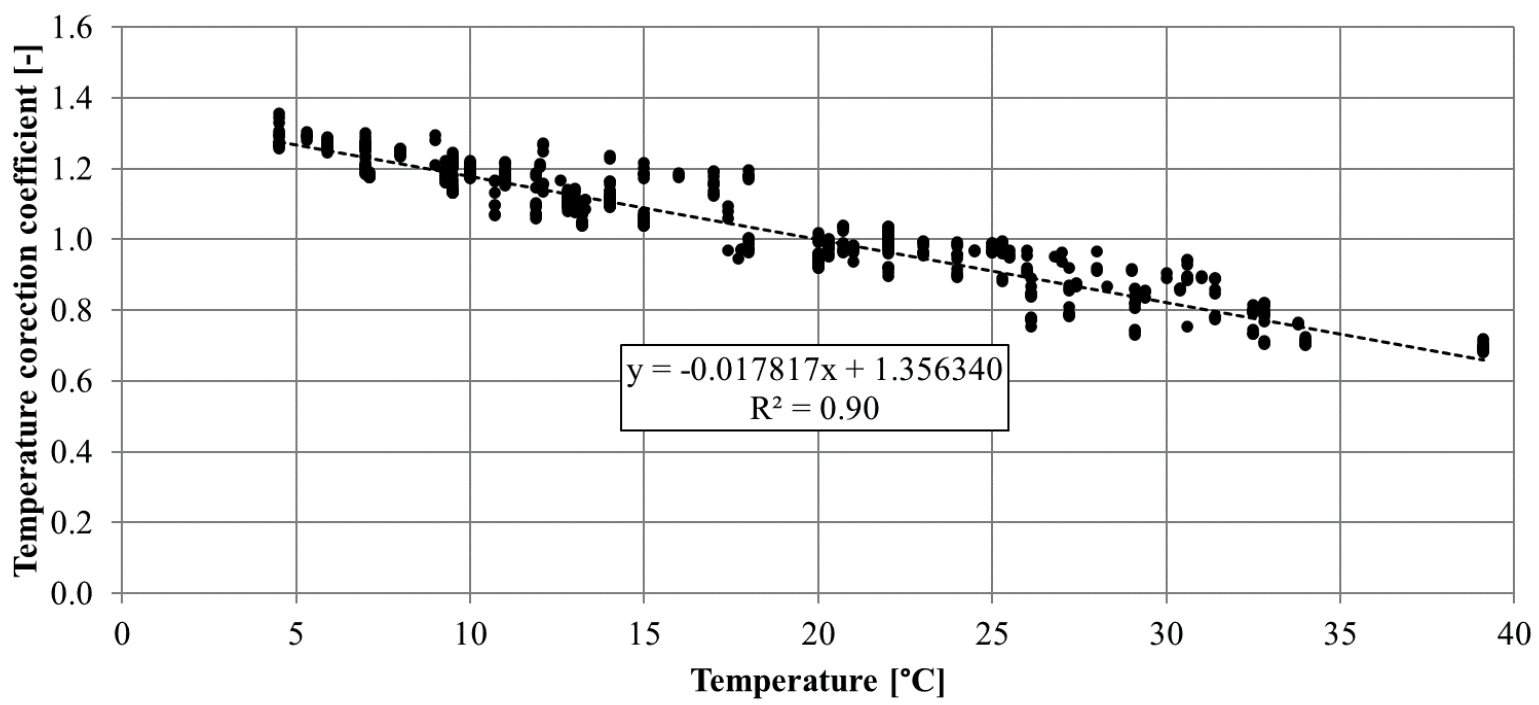

Figure 5 Regression curve of the temperature correction coefficient deflection $d_{0}$ (in the load axis) 
$d_{20}=$ deflection at the temperature of $20{ }^{\circ} \mathrm{C}$ calculated from the regression curve $[\mu \mathrm{m}]$,

$d_{T}=$ deflection at the temperature $T$ calculated from the regression curve $[\mu \mathrm{m}]$.

Subsequently, all of correction coefficients, calculated for a given sensor from the measurements on all of test sections, were grouped together and the final regression curve was derived (Figure 5). This procedure was applied for all the sensors and the regression curves according to distance of a sensor from the load axis given by Equations (5) - (10).

$$
\begin{aligned}
& c_{d, 0}=-0.017817 \cdot T+1.35634\left(R^{2}=0.90\right), \\
& c_{d, 300}=-0.012116 \cdot T+1.24232\left(R^{2}=0.82\right), \\
& c_{d, 600}=-0.007555 \cdot T+1.15110\left(R^{2}=0.64\right), \\
& c_{d, 900}=-0.0003958 \cdot T+1.07916\left(R^{2}=0.36\right), \\
& c_{d, 1200}=-0.002838 \cdot T+1.05676\left(R^{2}=0.24\right), \\
& c_{d, 1500}=-0.000631 \cdot T+1.01262\left(R^{2}=0.03\right),
\end{aligned}
$$

where:

$c_{d, \mathrm{i}}=$ deflection correction coefficient to the reference temperature of $20^{\circ} \mathrm{C}$ at a distance $i$ from loading axis [-].

As it was found out, the correction of deflections at sensors with spacing more than $900 \mathrm{~mm}$ from the load axis has marginal effect, the final equations for correction of deflections to the reference temperature of $20^{\circ} \mathrm{C}$ were derived only for e deflections $d_{0}-d_{900}$. They were set in the form:

$$
\begin{aligned}
& d_{0,20, \mathrm{cor}}=d_{0, T} \cdot(1+0.017817 \cdot(20-T)), \\
& d_{300,20, \mathrm{cor}}=d_{300, T} \cdot(1+0.012116 \cdot(20-T)), \\
& d_{600,20, \mathrm{cor}}=d_{600, T} \cdot(1+0.007555 \cdot(20-T)), \\
& d_{900,20, \mathrm{cor}}=d_{900, T} \cdot(1+0.003958 \cdot(20-T)),
\end{aligned}
$$

where:

$d_{\mathrm{i}, 20, c o r}=$ deflection at a distance $i$ from the load axis

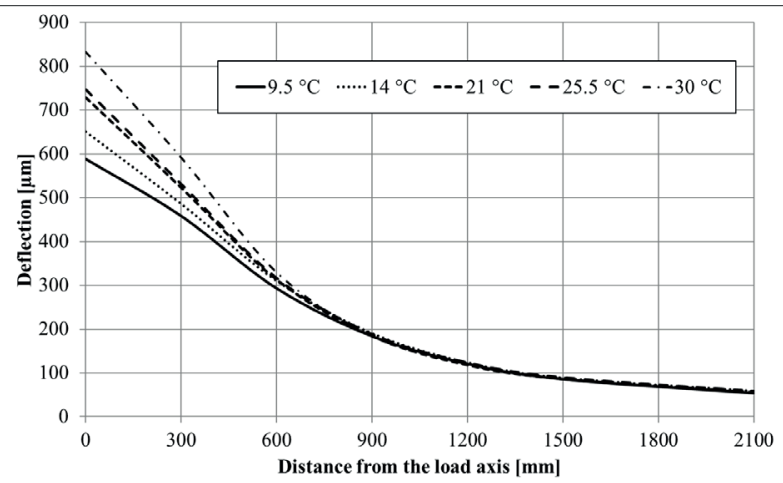

corrected to the reference temperature of $20^{\circ} \mathrm{C}[\mu \mathrm{m}]$, $d_{\mathrm{i}, T}=$ deflection measured at temperature $T$ at a distance $i$ from the load axis $[\mu \mathrm{m}]$,

$T=$ average temperature of asphalt layers in the depth of $40 \mathrm{~mm}\left[{ }^{\circ} \mathrm{C}\right]$.

All the measured deflection bowls were subsequently corrected according to the derived equations. Then, example of the temperature correction of the deflection bowls to the reference temperature of $20^{\circ} \mathrm{C}$, is shown in Figure 6.

The corrected deflection bowls were used in the next step as an input for the back-calculation of elasticity modulus of pavement layers.

\section{Comparison of the back-calculated moduli resulting from different approaches}

This stage included statistical processing of moduli of elasticity determined by the back-calculation from the original (non-corrected) deflection bowls and subsequently corrected to the temperature of $20{ }^{\circ} \mathrm{C}$ and moduli of elasticity determined by the back-calculation from deflection bowls corrected to the temperature of $20{ }^{\circ} \mathrm{C}$ before performing the back-calculation. In the ideal case the elasticity moduli determined by both approaches should reach the same values.

The average elasticity moduli of asphalt layers, determined according to the presented approaches on all the tested sections, are shown in Figure 7. Three groups of moduli can be observed, which are located around the moduli of elasticity of 4500, 5500 and $7000 \mathrm{MPa}$. The elasticity moduli in each of the groups, determined by both approaches (Figure 8), differ slightly at the sections $1-7$ and for these sections can be concluded that the used approach does not significantly affect the value of elasticity modulus recalculated to the reference temperature of $20{ }^{\circ} \mathrm{C}$. More significant deviations can be observed for sections 8-10 with the higher moduli determined by recalculation of the modulus determined from an original deflection bowl.

The previous findings regarding the differences between the elasticity moduli of asphalt layers that are resulting from two used approaches, lead to a question,

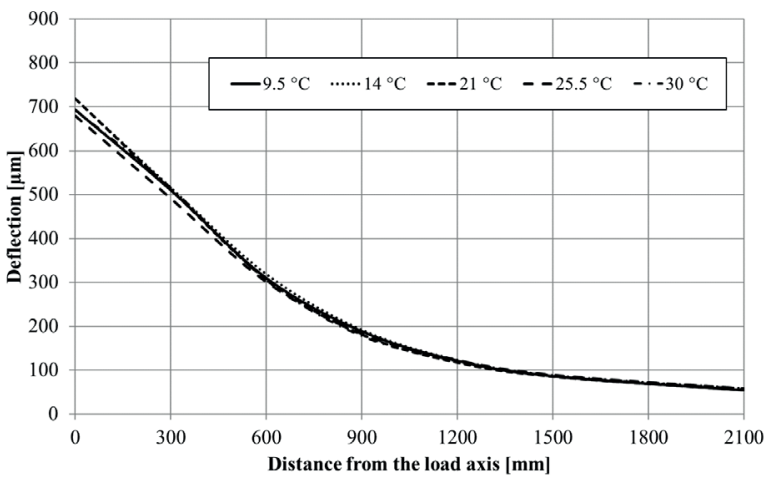

Figure 6 Deflection bowls measured at different temperatures (left) and corrected to the reference temperature of $20^{\circ} \mathrm{C}$; (right) section 5 , point 1 


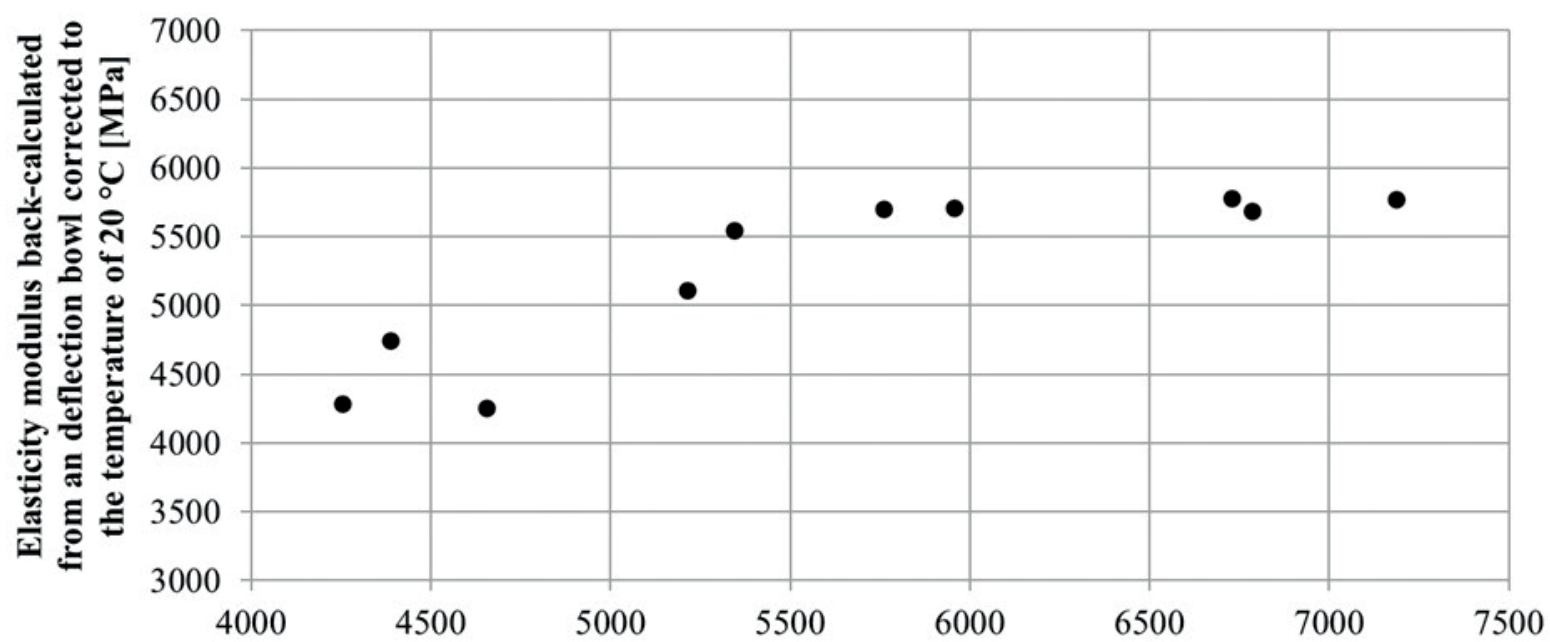

Elasticity modulus from an original deflection bowl corrected to the temperature of $20^{\circ} \mathrm{C}$ [MPa]

Figure 7 Average elasticity moduli of asphalt layers on tested sections

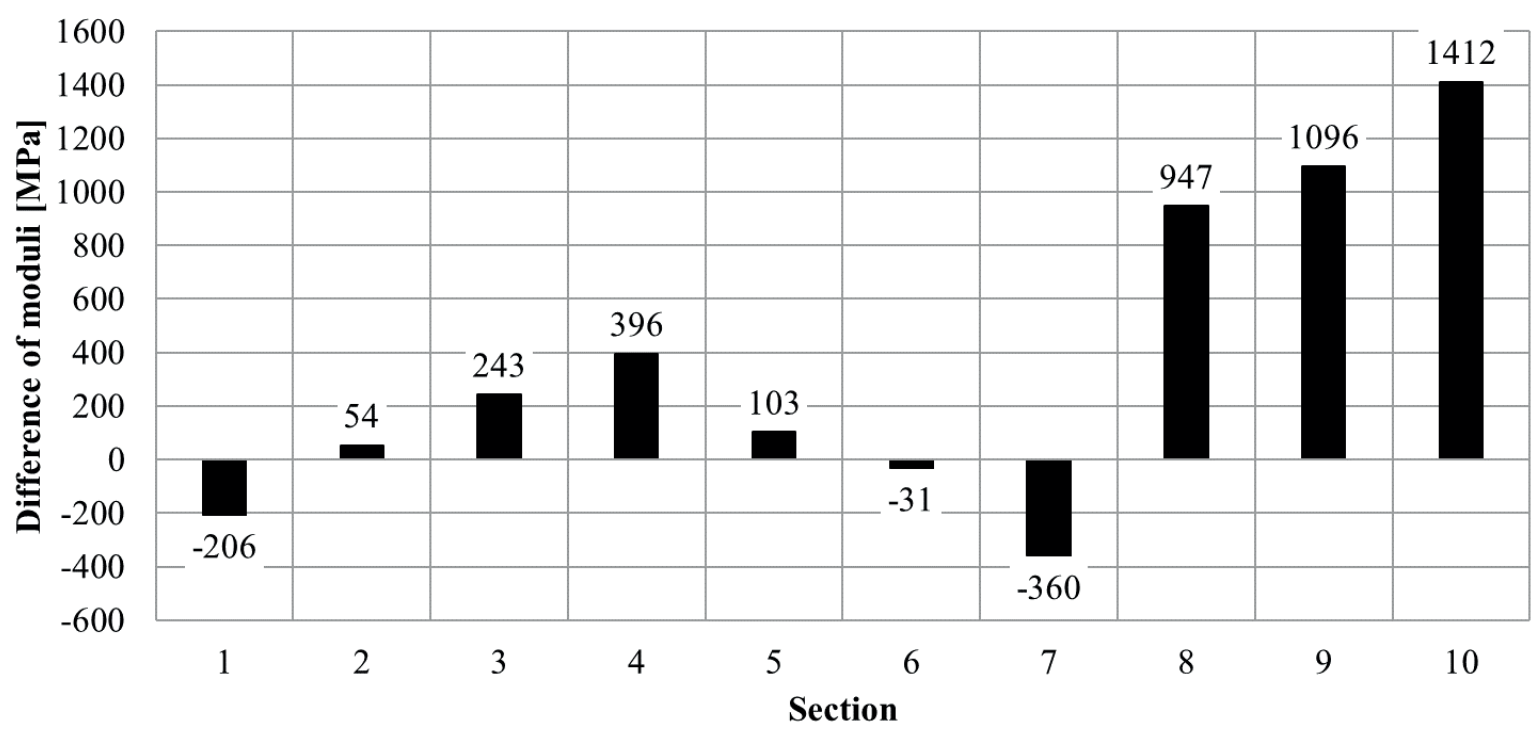

Figure 8 Differences in elasticity moduli of asphalt layers due to different approaches used for their determination

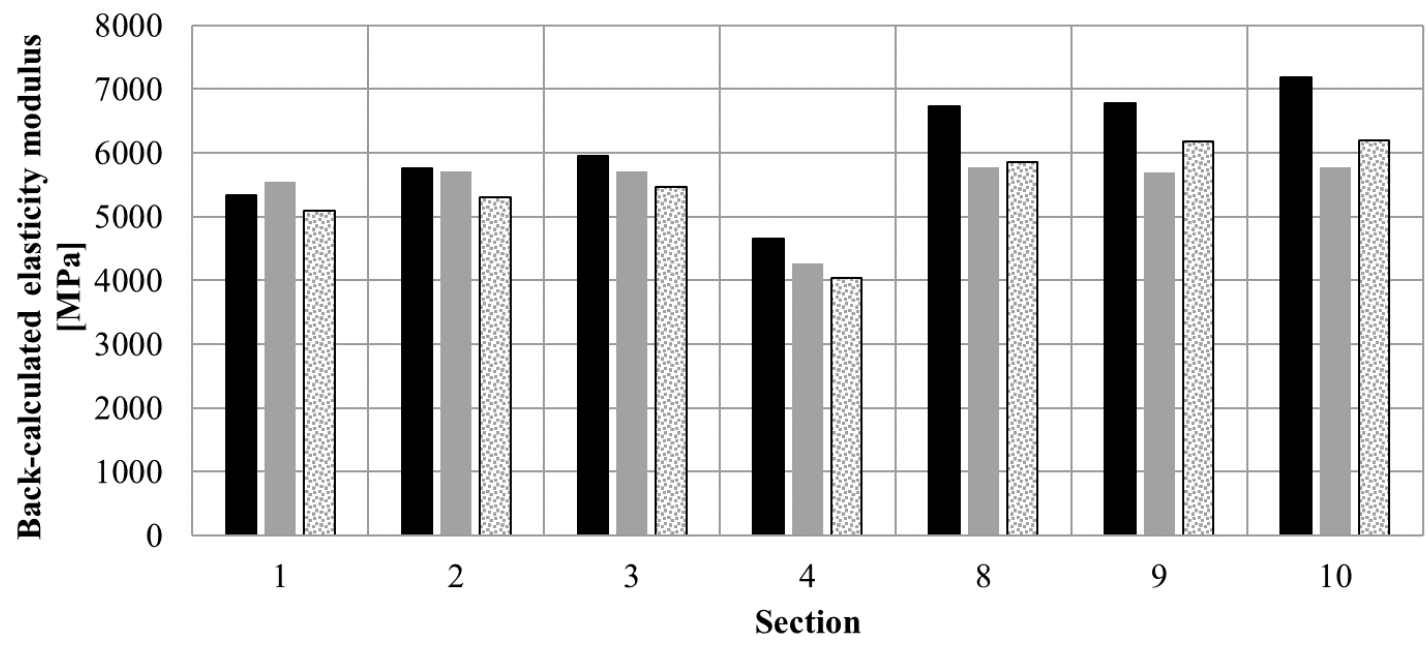

— original deflection bowl corrected deflection bowl $\quad$ deflection bowl measured at $20{ }^{\circ} \mathrm{C}$

Figure 9 Elasticity moduli of asphalt layers recalculated to temperature of $20^{\circ} \mathrm{C}$ and determined from measurements at temperature of $20^{\circ} \mathrm{C}$ 
which of approaches is more accurate. As both approaches recalculate moduli of deflection from a test temperature $T$ to the reference temperature of $20^{\circ} \mathrm{C}$, the comparison of average recalculated moduli to values back-calculated from the deflection bowl measured exactly at $20{ }^{\circ} \mathrm{C}$ can be a useful information. Unfortunately, measurements at $20{ }^{\circ} \mathrm{C}$ were performed only on some of the test sections. Nevertheless, it is clear from Figure 9 that in most cases the moduli back-calculated from the corrected deflection bowl are closer to the values calculated directly for the test temperature of $20^{\circ} \mathrm{C}$.

\section{Conclusions}

The presented research confirmed known effect of temperature of asphalt pavement on measured deflections and back-calculated elasticity moduli.

Temperature correction of back-calculated moduli or measured deflections to the reference temperature of $20^{\circ} \mathrm{C}$ was performed using temperature correction coefficient derived from regression curves.

Temperature correction coefficients applied on a measured deflection bowl were determined only for the sensors with spacing up to $900 \mathrm{~mm}$ from the load axis, since it was found out that the temperature has marginal effect on deflections measured by more distanced sensors.

The comparison of elasticity moduli of asphalt layers determined for the reference temperature of 20 ${ }^{\circ} \mathrm{C}$ according to two applied approaches (the correction of moduli back-calculated from an original (non-corrected) deflection bowl vs the correction of measured deflection bowl to the reference temperature of $20{ }^{\circ} \mathrm{C}$ and the subsequent back-calculation of moduli) has proven similarity of moduli for majority of the tested sections. On the remaining sections, the moduli back-calculated from an original deflection bowl were higher. When the corrected moduli, or those determined from the corrected deflection bowl, were compared to moduli backcalculated from the deflection bowls measured at the temperature of $20^{\circ} \mathrm{C}$ smaller differences were recorded for the moduli determined from the deflection bowl corrected to the reference temperature of $20^{\circ} \mathrm{C}$.

\section{Acknowledgement}

The research presented in this article was realized with the financial support of the Ministry of Transport of Czech Republic within the programme of long-term conceptual development of research institutions.

\section{References}

[1] KOMACKA, J., KORENKO, M., PIALA, J. Relation of temperature changes in asphalt pavements to pavement bearing capacity evaluation. Communications - Scientific Letters of the University of Zilina. 2007, 9(3), p. 33-36. ISSN 1335-4205, eISSN 2585-7878. Available from: http://komunikacie.uniza.sk/index.php/communications/ article/view/1139

[2] AKBARZADEH, H., BAYAT, A., SOLEYMANI, H., R. Analytical review of the HMA temperature correction factors from laboratory and falling weight deflectometer tests. International Journal of Pavement Research and Technology [online]. 2012, 5(1), p. 30-39. ISSN 1997-1400. Available from: http://www.ijprt.org.tw/files/sample/ V5N1\%2830-39\%29.pdf

[3] APPEA, A. K. Validation of FWD testing results at the Virginia smart road: theoretically and by instrument responses [online]. Ph.D. Thesis. Blacksburg, Virginia: Faculty of the Virginia Polytechnic Institute and State University, 2003. p. 293. Available from: http://hdl.handle.net/10919/26715

[4] BALTZER, S., JANSEN, J. M. Temperature correction of asphalt-moduli for FWD measurements. In: 4th International Conference Bearing Capacity of Roads and Airfields: proceedings. 1994. ISBN 9788790145149, p. 753-768.

[5] CHANG, J.-R., LIN, J.-D., CHUNG, W.-CH., CHEN, D.-H. Evaluating the structural strength of flexible pavements in Taiwan using the falling weight deflectometer. International Journal of Pavement Engineering [online]. 2002, 3(3), p. 131-141. ISSN 1029-8436. Available from: https://doi:10.1080/1029843021000067854

[6] CHEN, D.-H., BILYEU, J., LIN, H.-H., MURPHY, M. Temperature correction on falling weight deflectometer measurements. Transportation Research Record: Journal of the Transportation Research Board [online]. 2000, 1716(1), p. 30-39. ISSN 0361-1981. Available from: https://doi:10.3141/1716-04

[7] JOHNSON, A. M., BAUS, R. L. Alternative method for temperature correction of backcalculated equivalent pavement moduli. Transportation Research Record: Journal of the Transportation Research Board. 1992, 1355, p. 75-81. ISSN 0361-1981. Available from: http://onlinepubs.trb.org/Onlinepubs/trr/1992/1355/1355-009.pdf

[8] KIM, Y. R., HIBBS, B. O., LEE, Y. CH. Temperature correction of deflections and backcalculated asphalt concrete moduli. Transportation Research Record: Journal of the Transportation Research Board. 1995, 1473, p. 55 - 62. ISSN 0361-1981. Available from: http://onlinepubs.trb.org/Onlinepubs/trr/1995/1473/1473-007.pdf 
[9] PARK, H. M., KIM, Y. R., PARK, S. Temperature correction of multiload-level falling weight deflectometer deflections. Transportation Research Record: Journal of the Transportation Research Board [online]. 2002, 1806(1), p. 3-8. ISSN 0361-1981. Available from: https://doi:10.3141/1806-01

[10] STRAUBE, E., JANSEN, D. Temperature correction of falling weight deflectometer measurements. In: 8th International Conference Bearing Capacity of Roads, Railways and Airfields BCR2A'09: proceedings. 2009. ISBN 9780415871990, p. 789-798.

[11] STUBSTAD, R. N., BALTZER, S., LUKANEN, E. O., ERTMAN-LARSEN, H. J. Prediction of AC Mat temperatures for routine load/deflection measurements. In: 4th International Conference Bearing Capacity of Roads and Airfields: proceedings. Minneapolis, 1994. ISBN 9788790145149, p. 401 - 412.

[12] European Commission. COST 336 Use of falling weight deflectometers in pavement evaluation. Final report of the action. 2. ed. Luxembourg: Office for Official Publications of the European Communities, 2005. p. 392.

[13] KOMACKA, J. Change of bearing capacity characteristics of asphalt pavement. Communications - Scientific Letters of the University of Zilina. 2011, 13(3), p. 52-55. ISSN 1335-4205, eISSN 2585-7878. Available from: http://komunikacie.uniza.sk/index.php/communications/article/view/863

[14] ASTM D7228-06a Standard test method for prediction of asphalt-bound pavement layer temperatures. West Conshohocken: ASTM International, 2020.

[15] PARK, D.-Y., BUCH, N., CHATTI, K. Effective layer temperature prediction model and temperature correction via falling weight deflectometer deflections. Transportation Research Record: Journal of the Transportation Research Board [online]. 2001, 1764(1), p. 97-111. ISSN 0361-1981. Available from: https://doi:10.3141/1764-11

[16] ULLIDTZ, P. Pavement analysis. Developments in civil engineering. Amsterdam: Elsevier Science Publishers B. V., 1987. ISBN 0-444-42817-8, p. 318. 